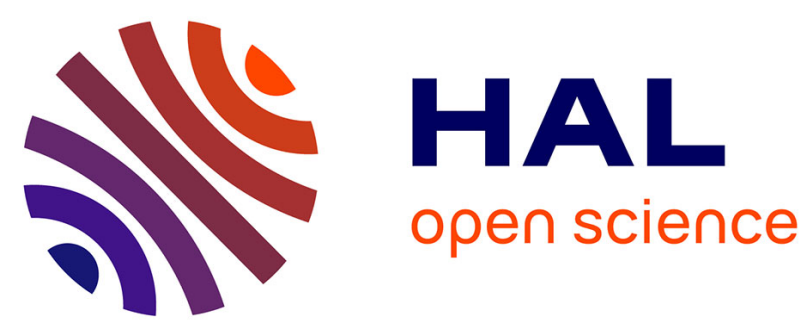

\title{
A homozygous balanced reciprocal translocation suggests LINC00237 as a candidate gene for MOMO (macrosomia, obesity, macrocephaly, and ocular abnormalities) syndrome
}

Phi Yen Vu, Jérôme Toutain, David Capellen, Marie-Ange Delrue, Hussein Daoud, Moneim Azza Abd El, Pascal Barat, Orianne Montaubin, Françoise Bonnet, Zong Qi Dai, et al.

\section{- To cite this version:}

Phi Yen Vu, Jérôme Toutain, David Capellen, Marie-Ange Delrue, Hussein Daoud, et al.. A homozygous balanced reciprocal translocation suggests LINC00237 as a candidate gene for MOMO (macrosomia, obesity, macrocephaly, and ocular abnormalities) syndrome. American Journal of Medical Genetics Part A, 2012, 158A (11), pp.2849-2856. 10.1002/ajmg.a.35694 . hal-02649559

\section{HAL Id: hal-02649559 \\ https://hal.inrae.fr/hal-02649559}

Submitted on 29 May 2020

HAL is a multi-disciplinary open access archive for the deposit and dissemination of scientific research documents, whether they are published or not. The documents may come from teaching and research institutions in France or abroad, or from public or private research centers.
L'archive ouverte pluridisciplinaire HAL, est destinée au dépôt et à la diffusion de documents scientifiques de niveau recherche, publiés ou non, émanant des établissements d'enseignement et de recherche français ou étrangers, des laboratoires publics ou privés. 


\section{A Homozygous Balanced Reciprocal Translocation Suggests LINC00237 as a Candidate Gene for MOMO (Macrosomia, Obesity, Macrocephaly, and Ocular Abnormalities] Syndrome}

Phi Yen Vu, ${ }^{1,2,3}$ Jérôme Toutain, ${ }^{2 *}$ David Cappellen, ${ }^{4,5}$ Marie-Ange Delrue, ${ }^{2}$ Hussein Daoud, ${ }^{6}$ Azza Abd El Moneim, ${ }^{2}$ Pascal Barat, ${ }^{7,8}$ Orianne Montaubin, ${ }^{2}$ Françoise Bonnet, ${ }^{9}$ Zong Qi Dai, ${ }^{2}$ Christophe Philippe, ${ }^{10}$ Cong Toai Tran, ${ }^{3}$ Caroline Rooryck, ${ }^{1,2}$ Benoît Arveiler, ${ }^{1,2}$ Robert Saura, ${ }^{2}$ Sylvain Briault, ${ }^{6}$ Didier Lacombe, ${ }^{1,2}$ and Laurence Taine ${ }^{2}$

${ }^{1}$ Univ. Bordeaux, Maladies Rares: Génétique et Métabolisme (MRGM), Bordeaux, France

${ }^{2} \mathrm{CHU}$ Bordeaux, Génétique médicale, Bordeaux, France

${ }^{3}$ Laboratoire d'Histologie-Embryologie-Génétique, UTC Ho Chi Minh City, Ho Chi Minh, Vietnam

${ }^{4}$ Univ. Bordeaux, Histologie et pathologie moléculaire des tumeurs, Bordeaux, France

${ }^{5} \mathrm{CHU}$ Bordeaux, Biologie des tumeurs, Pessac, France

${ }^{6}$ Faculté de Médecine de Tours, INSERM U619, Tours, France

?Univ. Bordeaux, Nutrition et neurobiologie intégrée, Bordeaux, France

${ }^{8} \mathrm{CHU}$ Bordeaux, Endocrinologie pédiatrique, Bordeaux, France

${ }^{9}$ Institut Bergonié, Laboratoire de génétique moléculaire, Bordeaux, France

${ }^{10} \mathrm{CHU}$ Nancy, Génétique médicale, Vandœuvre-lès-Nancy, France

Manuscript Received: 7 April 2012; Manuscript Accepted: 29 August 2012

Macrosomia, obesity, macrocephaly, and ocular abnormalities syndrome (MOMO syndrome) has been reported in only four patients to date. In these sporadic cases, no chromosomal or molecular abnormality has been identified thus far. Here, we report on the clinical, cytogenetic, and molecular findings in a child of healthy consanguineous parents suffering from MOMO syndrome. Conventional karyotyping revealed an inherited homozygous balanced reciprocal translocation $(16 ; 20)(q 21 ; p 11.2)$. Uniparental disomy testing showed biparental inheritance for both derivative chromosomes 16 and 20. The patient's oligonucleotide array-comparative genomic hybridization profile revealed no abnormality. From the homozygous balanced reciprocal translocation (16;20)(q21;p11.2), a positional cloning strategy, designed to narrow $16 \mathrm{q} 21$ and 20p11.2 breakpoints, revealed the disruption of a novel gene located at 20p11.23. This gene is now named LINC00237, according to the HUGO (Human Genome Organization) nomenclature. The gene apparently leads to the production of a non-coding RNA. We established that LINC00237 was expressed in lymphocytes of control individuals while normal transcripts were absent in lymphocytes of our MOMO patient. LINC00237 was not ubiquitously expressed in control tissues, but it was notably highly expressed in the brain. Our results suggested autosomal recessive inheritance of MOMO syndrome. LINC00237 could play a role in the pathogenesis of this syndrome and could
How to Cite this Article:

Vu PY, Toutain J, Cappellen D, Delrue M-A, Daoud H, Moneim AAE, Barat P, Montaubin O, Bonnet F, Dai ZQ, Philippe C, Tran CT, Rooryck C, Arveiler B, Saura R, Briault S, Lacombe D, Taine L. 2012. A homozygous balanced reciprocal translocation suggests LINC00237 as a candidate gene for MOMO (macrosomia, obesity, macrocephaly and ocular abnormalities) syndrome.

Am J Med Genet Part A 158A:2849-2856.

Additional supporting information may be found in the online version of this article.

Grant sponsor: CHU-Bordeaux AOI 2003-2005 Promotion.

The authors declare no conflict of interest.

Jérôme Toutain and David Cappellen contributed equally to this work. ${ }^{\star}$ Correspondence to:

Jérôme Toutain, Laboratoire de Cytogénétique, Service de Génétique Médicale, Maternité Pellegrin, CHU de Bordeaux, Place Amélie RabaLéon, 33076 Bordeaux Cedex, France.

E-mail: jerome.toutain@chu-bordeaux.fr Article first published online in Wiley Online Library (wileyonlinelibrary.com): 3 October 2012

DOI 10.1002/ajmg.a.35694 
provide new insights into hyperphagia-related obesity and intellectual disability. (c) 2012 Wiley Periodicals, Inc.

Key words: MOMO syndrome; hyperphagia; obesity; intellectual disability; non-coding RNA

\section{INTRODUCTION}

Macrosomia, obesity, macrocephaly, and ocular abnormalities syndrome (MOMO syndrome, OMIM 157980) is an extremely rare syndrome with only four patients reported to date [Wallerstein and Sugalski, 2010]. The main features of this syndrome are early onset obesity associated with intellectual disability, macrosomia, macrocephaly, ocular abnormalities (retinal coloboma and nystagmus), downward slant of palpebral fissures, and femoral recurvation [Moretti-Ferreira et al., 1993; Zannolli et al., 2000; Giunco et al., 2008; Wallerstein and Sugalski, 2010]. Although the molecular basis of MOMO syndrome remains unknown, the four patients previously described were from nonconsanguineous families, suggesting autosomal dominant inheritance [Moretti-Ferreira et al., 1993; Zannolli et al., 2000].

Cytogenetic results showing homozygous balanced reciprocal translocations are exceptional [Zaki et al., 2007]. In patients with abnormal phenotypes, these rearrangements can theoretically help geneticists identify the basis of recessive genetic conditions using positional cloning strategies.

In this report, we present the clinical, cytogenetic, and molecular findings from a patient suffering from MOMO syndrome. Our patient presented a homozygous balanced reciprocal translocation $(16 ; 20)(\mathrm{q} 21 ; \mathrm{p} 11.23)$ inherited from healthy consanguineous parents. We hypothesized that this translocation could disrupt a gene of pathogenic importance for MOMO syndrome. Positional cloning strategies were used to isolate a candidate gene for this syndrome.

\section{MATERIALS AND METHODS}

\section{Clinical Report}

A French gypsy boy was admitted for early onset obesity. He was the only child of healthy consanguineous parents. This child was born at term with macrosomia $(4,850 \mathrm{~g} ;+3 \mathrm{SD})$. Since he was 18 months old, he had significant hyperphagia. At $61 / 2$ years, he weighed $74 \mathrm{~kg}$ $(>3 \mathrm{SD})$ and measured $124 \mathrm{~cm}(+1.5 \mathrm{SD}$; body mass index [BMI]: $>48$ [ $>3$ SD]; Fig. 1A). His OFC was $57 \mathrm{~cm}$ (>3 SD). Other minor dysmorphic features were noted: bulbous nose, almond-shaped eyes, and brachydactyly. He also had hypogenitalism, a marked deformation of the lower limbs with an important femoral recurvation (Fig. 1A), and arterial hypertension. Radiographs of the lower limbs confirmed his femoral recurvation (Fig. 1B). He showed signs of a moderate intellectual disability and underwent special education. At $81 / 2$ years, he could neither read nor write. At age 11 years, he lost his ability to walk due to bowed legs and obesity. At $141 / 2$ years, he weighed $170 \mathrm{~kg}(>3 \mathrm{SD})$, measured $158 \mathrm{~cm}$ ( -2 SD; BMI: $>68$ [>3 SD]), and had an OFC of $60 \mathrm{~cm}(>3 \mathrm{SD})$. Ophthalmological examination highlighted bilateral temporal

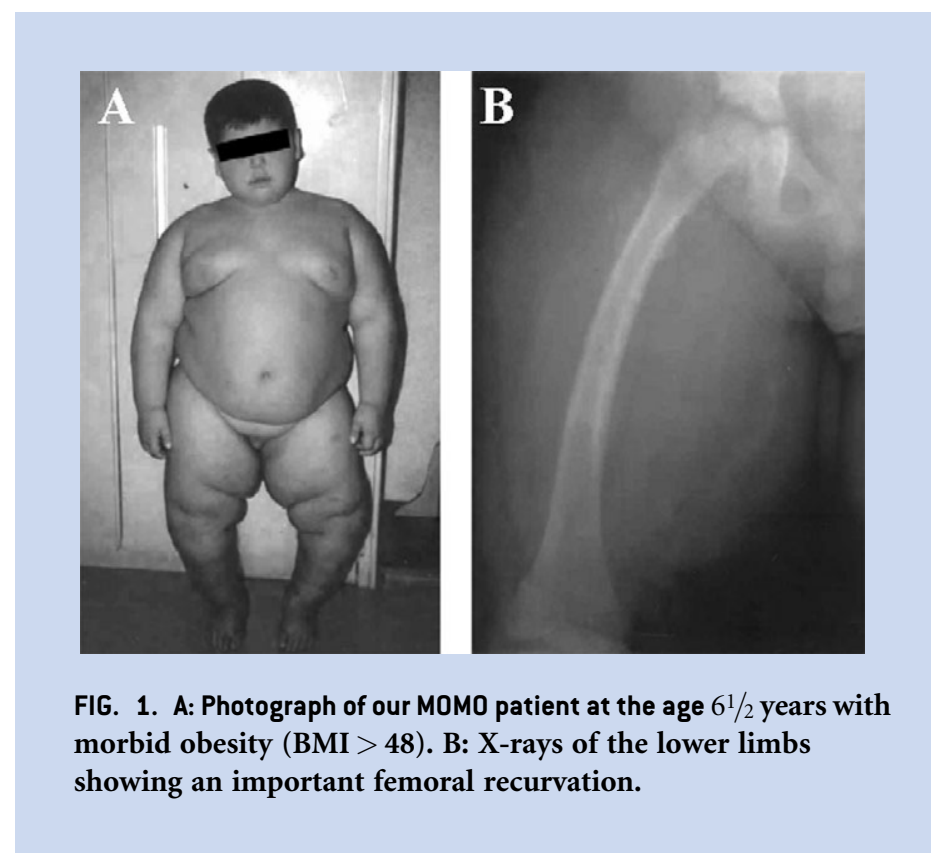

optic atrophy. The child also had a moderate bilateral astigmatism. Molecular studies for Prader-Willi and Fragile X syndrome were negative. A diagnosis of MOMO syndrome was suggested.

\section{Conventional Karyotyping, Uniparental Disomy Testing, and Oligonucleotides Array-Comparative Genomic Hybridization}

Lymphocytes were cultured with additional phytohemagglutinin stimulation. Chromosomes were treated with 5-Bromodeoxyuridine, exposed to light and heat, and colored using Giemsa stains to produce good resolution R-bands. Karyotypes were established at a level of resolution of up to 550 bands per haploid set.

Uniparental disomy (UPD) testing was carried out on genomic DNAs extracted from peripheral blood lymphocytes. Microsatellite markers for chromosome 16 (D16S489, D16S672, D16S678, and D16S686) and for chromosome 20 (D20S117, D20S428, D20S446, and D20S453) were studied. Segregation analysis was performed using multiplex fluorescent polymerase chain reaction (PCR) assays and fragment analysis on an ABI prism 310 DNA sequencer (Applied Biosystems, Carlsbad, CA).

Oligonucleotide array-comparative genomic hybridization (array-CGH) was performed using a $105 \mathrm{~K}$ oligonucleotide array (Agilent Technologies, Inc., Santa Clara, CA). The patient's genomic DNA was hybridized against a reference DNA. Copy number variations were screened against databases of known variants.

\section{Fluorescence In Situ Hybridization Analysis}

Fluorescence in situ hybridization (FISH) analyses were completed on metaphase spreads obtained from Epstein-Barr virus immortalized peripheral lymphocytes. Multiple bacterial artificial chromosome (BAC) and p1-derived artificial chromosome (PAC) clones targeting chromosomes 16 and 20 were used (Invitrogen, Carlsbad, CA). BAC and PAC clones were labeled using the Dig-Nick Translation Mix (Roche Applied Science, Indianapolis, IN) and the 
BioNick Labelling System (Invitrogen). Centromeric chromosomes 16 and 20 probes were used as controls (Abbott Molecular, Inc., Abbott Park, IL).

\section{Long Range PCR Sub-Cloning and Direct Sequencing}

Long range PCR (LR-PCR) was performed for the sub-cloning of a region of about $7 \mathrm{~kb}$ using the Expand Long Template PCR System Kit (Roche Applied Science). Primers for the LR-PCR, reverse transcriptase PCR (RT-PCR), and rapid amplification of cDNA ends (RACE) were designed using Primer 3, a web-based interface. Forward and reverse primers for the LR-PCR were designed in order to span regions separated from each other of about $1 \mathrm{~kb}$ (Supplementary Table I). LR-PCR products of derivatives chromosomes junctions were purified using MicroSpin S-300 HR Columns (Amersham Biosciences, Piscataway, NJ) and were sequenced using the BigDye Terminator v1.1 Cycle Sequencing Kit on an ABI 3130 Genetic Analyser (Applied Biosystems).

\section{Expression Analysis}

Expression of the genes around the two breakpoints was studied by RT-PCR with cDNA from several types of cells including brain, adipose tissue, fibroblast and lymphoblast cell lines (Clontech, Mountain View, CA). Total RNA was extracted using the Totally RNA Kit (Ambion, Carlsbad, CA) and treated with Deoxyribonuclease I-Amplification Grade (Invitrogen). The reverse transcription was completed using SuperScript II Reverse Transcriptase (Invitrogen). PCR reactions were performed using an AmpliTaq Gold DNA Polymerase (Applied Biosystems; primers listed in Supplementary Table II). Quantitative PCR of cDNA was obtained in the lymphoblast cell lines using Brilliant SYBR Green QPCR Master Mix (Stratagene, La Jolla, CA). The results were normalized using the expression level of beta-actin (Clontech).

\section{Full Length Gene Cloning}

$5^{\prime}$ and $3^{\prime}$ RACE was performed in the lymphoblast cell lines with the $5^{\prime}$ and $3^{\prime}$ RACE System (Invitrogen). Total RNA was reverse transcribed using the oligo-dT primer. In the $3^{\prime}$ RACE experiment, we performed a PCR with a gene specific primer in combination with the supplied $3^{\prime}$ adaptor primer. Nested-PCR was also done using another gene specific primer in combination with the supplied nested primer. In the $5^{\prime}$ RACE experiment, a $5^{\prime}$ tailing step preceded the PCR and the nested-PCR which had two gene specific primers in combination with the supplied $5^{\prime}$ adaptor primer. Full length isoforms in the brain were obtained by $5^{\prime}$ and $3^{\prime}$ RACE using the Human Brain Marathon-Ready cDNA (Clontech) in accordance with the manufacturers' instructions. The majority of RACE-PCRs was performed with gene specific primers and different nested gene specific primers in combination with the supplied adaptor primer, AP1, and nested adaptor primer, AP2 (See Supplementary Table I in Supporting Information online).

\section{Mutation Screening of the Candidate Gene}

Seven patients with a MOMO-like phenotype were chosen for mutation analysis of the disrupted candidate gene (clinical signs listed in Supplementary Table III in Supporting Information online). We performed direct sequencing as described above, including all exon-intron boundaries.

\section{RESULTS}

Conventional karyotyping, uniparental disomy testing, and oligonucleotides array-comparative genomic hybridization.

Conventional karyotyping revealed that our patient had a homozygous apparently balanced reciprocal translocation $(16 ; 20)(q 21 ; p 11.2$; Fig. 2A). Karyotypes of his mother and father were 46,XX,t(16;20)(q21;p11.2) and 46,XY,t(16;20)(q21;p11.2), respectively (Fig. 2A). The bi-parental inheritance of chromosomes 16 and 20 in our MOMO syndrome patient was confirmed by markers D16S6785 (16p13.12), D20S4285 (20q13.2), and D20S446 (20p12.1). The oligonucleotide array-CGH analysis showed no genomic abnormality in our patient.

\section{Fluorescence In Situ Hybridization Analysis}

A physical map of 16q21 and 20p11.2 was established using FISH analysis. BAC RP11-467O15 and PAC RP5-872K7 were able to identify that the translocation breakpoints in our patient were on $16 \mathrm{q} 21$ and 20p11.23 (Fig. 2B). The signal intensity analysis performed with overlapping FISH probes restricted each breakpoint area to about $60 \mathrm{~kb}$ of critical regions.

\section{Long Range PCR Sub-Cloning and Direct Sequencing}

The absence of amplification of DNA from MOMO patient lymphocytes indicated that the breakpoints were between primers $7 \mathrm{~F}$ and $7 \mathrm{R}$ on chromosome $16 \mathrm{q} 21$ and between primers $5 \mathrm{~F}$ and $5 \mathrm{R}$ on chromosome 20p11.23 (Fig. 3A). The PCR performed on DNA from the MOMO patient with these two pairs of primers, each combining one primer on chromosome 16q21 and one primer on chromosome 20p11.23, allowed amplification of hybrid der(16)) $(16 ; 20)(\mathrm{q} 21 ; 20 \mathrm{p} 11.23)$ and $\operatorname{der}(20) \mathrm{t}(16 ; 20)(\mathrm{q} 21 ; 20 \mathrm{p} 11.23)$ DNA fragments, corresponding to each derivative chromosome (Fig. 3B and Supplementary Table IV in Supporting Information online).

DNA sequencing of the LR-PCR products allowed us to characterize the two breakpoints and revealed that the translocations occurred at the nucleotide position $62,671,762$ of germline chromosome 16 with a deletion of three nucleotides and at the nucleotide position $21,078,333$ on germline chromosome 20 with a deletion of eight nucleotides (nucleotide positions determined on chromosome sequences assemblies from the NCBI database: http://www.ncbi.nlm.nih.gov, March 18, 2012; Fig. 4). The breakpoint at 16q21 did not disrupt any known or predicted gene, whereas the breakpoint at 20p11.23 was located within the second intron of a novel gene named LINC00237, predicted to give rise to a non-protein-coding RNA (npcRNA).

\section{Expression Analysis}

RT-PCR analysis was performed to evaluate the expression of MOMO syndrome candidate genes (Fig. 5A), surrounding the 


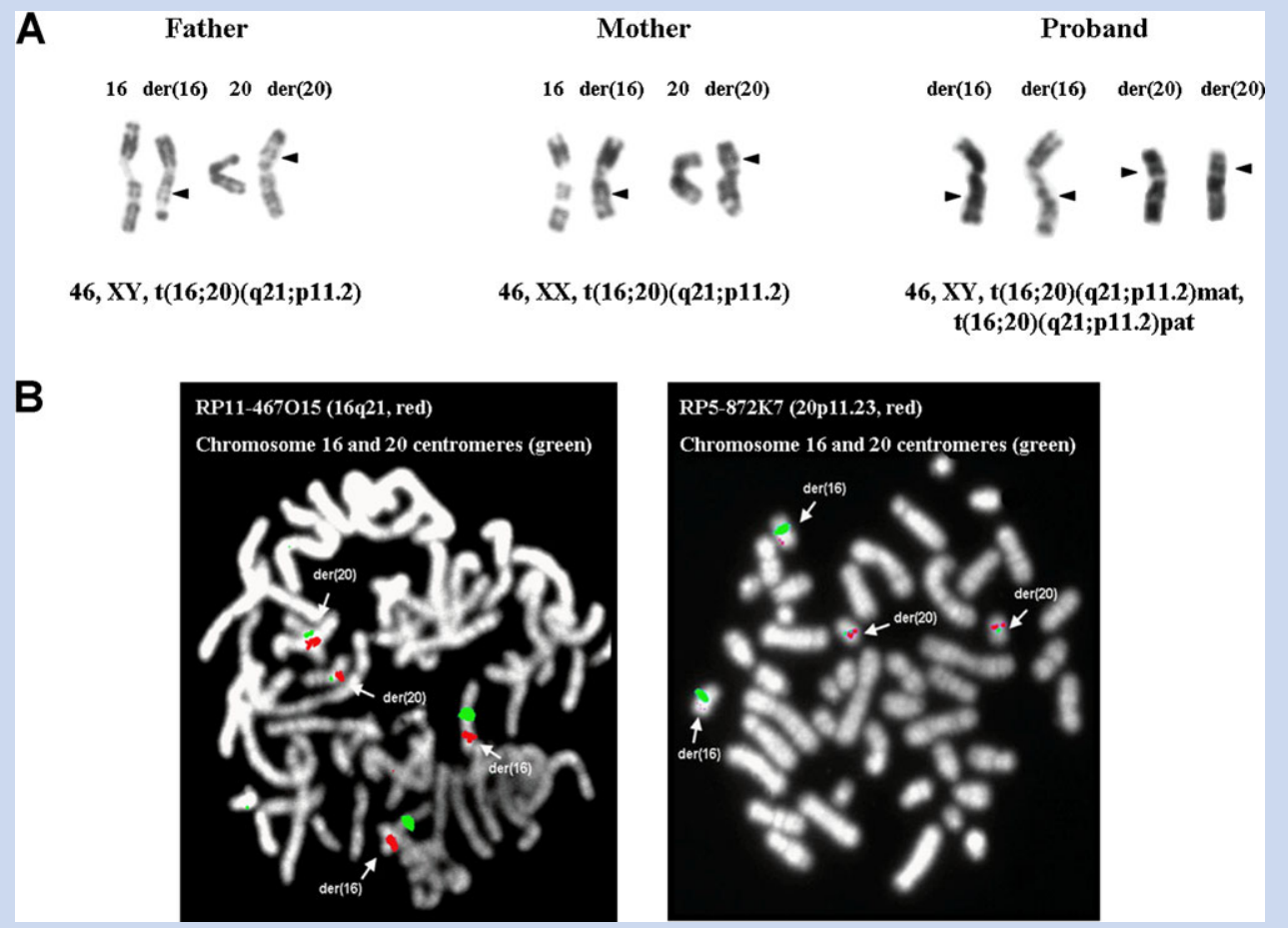

FIG. 2. Conventional karyotyping and fluorescence in situ hybridization (FISH) analysis. A: Partial conventional karyotyping showing heterozygous $t(16 ; 20)$ (q21;p11.2) translocations in the parental lymphocytes; and homozygous in the proband's lymphocytes. B: FISH analysis on metaphase spreads from proband's lymphocytes. Bacterial artificial chromosomes (BAC) probes RP11-467015 [16q21] and RP5-872K? [20p11.23] overlapping the chromosome breakpoints were labeled with Spectrum Red and appear in red, while control centromeric probes on chromosomes 16 and 20 labeled with FITC appear in green. Arrows identify both derivative chromosomes 16 and 20.

A Long range PCR amplification of germline DNA fragments

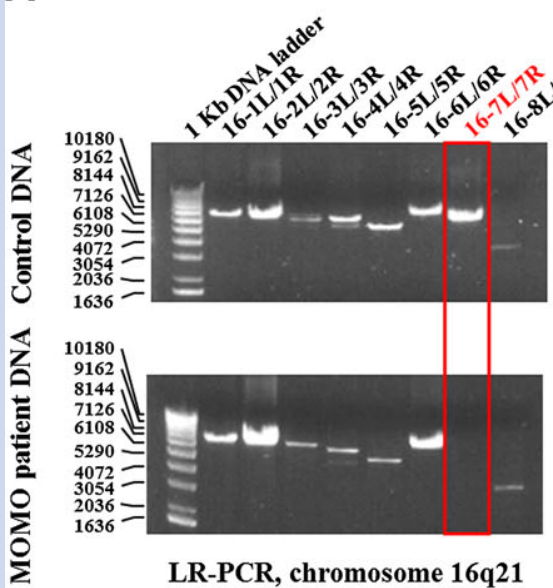

B PCR amplification of derivative translocated chromosomes
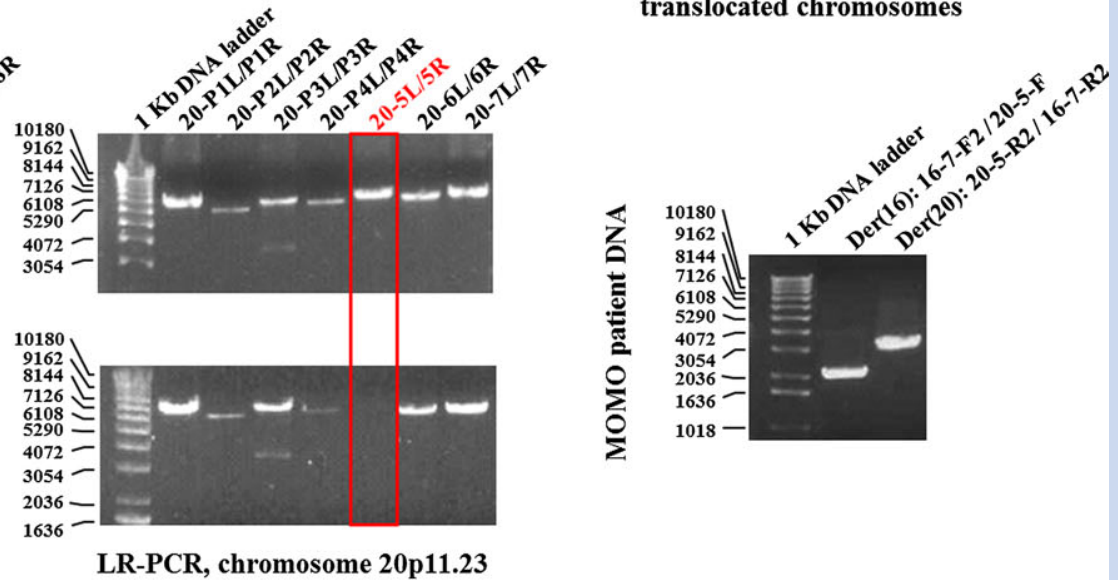

FIG. 3. A: Long range polymerase chain reaction (LR-PCR) amplification of DNA fragments spanning a 55 kb region on chromosome $16 q 21$ (left panels] and a $54 \mathrm{~kb}$ region on chromosome 20p11.23 (right panels]. All fragments were amplified from control lymphocytes DNA from a healthy donor [top panels]. The absence of amplification of DNA from MOMO patient lymphocytes [bottom panels] map the breakpoints between primers ?F and $7 R$ on chromosome 16q21 and between primers 5F and 5R on chromosome 20p11.23. B: PCR performed on DNA from the MOMO patient with two pairs of primers, each combining one primer on chromosome 16q21 and one primer on chromosome 20p11.23, allowed amplification of hybrid $\operatorname{der}(16) t(16 ; 20)(q 21 ; p 11.23)$ and $\operatorname{der}[20] t(16 ; 20)\{q 21 ; p 11.23]$ DNA fragments, corresponding to each derivative translocated chromosome. 


\section{Sequence of germline Chromosome 16q21 \\ Strand: \\ Sense: \\ Translocated chromosomes junction position Breakpoint on Chromosome 16

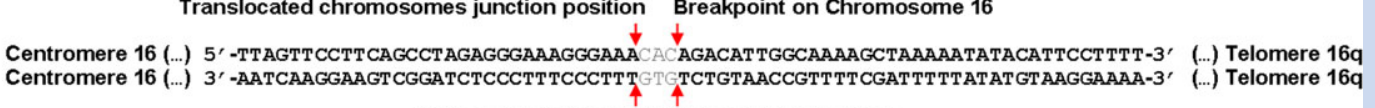 \\ 3 base pairs deleted at the translocations junctions}

Sequence of germline Chromosome 20p11.23

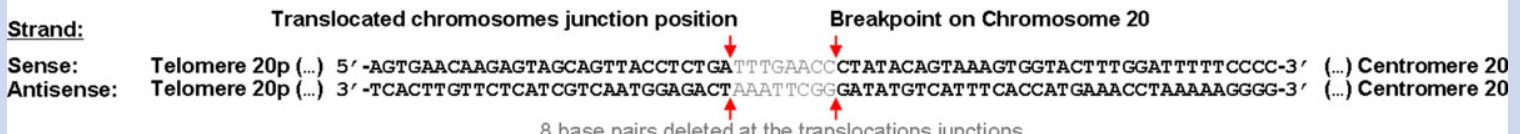

Sequence of derivative Chromosome der(16), long arm

Strand:

Sense:

Chromosome 16q21 Chromosome 20p11.23-pter

Antisense:

Centromere 16 (...) 5' 5 -TTAGTTCCTTCAGCCTAGAGGGAAAGGGAAMTCAGAGGTAACTGCTACTCTTGTTCACT-3' (...) Telomere 20p

Centromere 16 (...) $3^{\prime}$-AATCAAGGAAGTCGATCTCCCTT TCCCTT TAGTCTCCATTGACGATGAGAACAAGTGA-3' (...) Telomere 20p

\section{Sequence of derivative Chromosome der(20), short arm}

Strand:

Chromosome 16qter-q21

Chromosome 20p11.23

Sense:

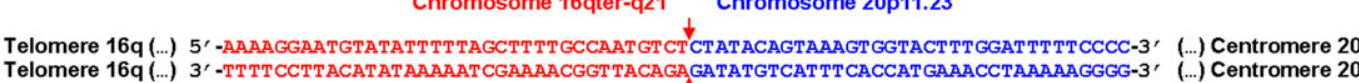

FIG. 4. Partial sequences of normal germline chromosomes 16q21 and 20p11.23, and der[16] and der[20] derivative translocated chromosome polymerase chain reaction (PCR) amplified DNA fragments. Arrows indicate breakpoints and junction positions on germline and derivative chromosomes. The breakpoint on 16q21 was mapped between nucleotide positions $62,671,759$ and $62,671,760$ of germline chromosome 16 , and the breakpoint on 20p11.23 was mapped between nucleotide positions 21,078,333 and 21,078,334 of germline chromosome 20 (nucleotide positions determined on chromosome sequences assemblies from the NCBI database: http://www.ncbi.nlm.nih.gov, March 18, 2012].

translocation breakpoints at 16q21 and 20p11.23. Expression of candidate genes was monitored in cells and tissues linked to the disease process (adipocytes, fibroblasts, and brain) obtained from deceased healthy individuals upon autopsy. Expression in these normal tissues and cells was compared to that in MOMO patient lymphoblasts, used as a diseased cellular model, and that in his parents' lymphoblasts, carrying the same balanced chromosomal translocation in a heterozygous state. This analysis revealed that, with one notable exception, candidate genes expressed in normal tissues and cells showed no significant alteration in MOMO syndrome patient cells (Fig. 5B). CDH8 (cadherin 8, type 2), located $601 \mathrm{~kb}$ upstream from the 16q21 MOMO syndrome chromosomal breakpoint (Fig. 5A) was expressed in control adipocytes and brain, but was not expressed in control and MOMO patient lymphoblasts (Fig. 5B), preventing its evaluation as a candidate gene. However, its very large distance from the breakpoint did not make it a priority candidate. The 20p11.23 region contains 10 genes (Fig. 5A), in particular several transcription regulator genes (INSM1, XRN2, NKX2-4, NKX2-2, PAX1, and FOXA2), and the breakpoint on chromosome 20 could potentially alter the expression in any of them. INSM1, NKX2-4, NKX2-2, PAX1 were not expressed in normal cells or tissues and in MOMO patient lymphoblasts (Fig. 5B and data not shown), indicating that they are unlikely candidates for the MOMO syndrome. C20orf26, RALGAPA2, PLK1S1, XRN2, and FOXA2 showed similar expression in control and MOMO patient lymphoblasts (Fig. 5B), ruling out their implication as MOMO syndrome genes.

In contrast, RT-PCR analysis showed that LINC00237, not expressed in fibroblasts and adipocytes, was expressed in the brain and in lymphoblasts from control individuals, whereas its transcripts were absent in lymphoblasts from our MOMO syndrome patient (Fig. 5B). This observation was confirmed by quantitative PCR analysis (Fig. 5C). Quantitative PCR analysis also revealed that, as compared to controls, expression of LINC00237 was reduced by around 50\% in lymphoblasts from the patient's parents. Both parents carried the translocation in a heterozygous state (Fig. 5C). Altogether, these data indicated that the homozygous MOMO syndrome translocation inactivated LINC00237.

\section{Characterization of LINC00237 and Its Products}

Rapid amplification of complementary DNA (cDNA) ends (RACE analysis) was performed on cDNA from control lymphoblasts and identified a variant containing two exons, herein named exon $1 \beta$ and exon 2 (Fig. 5D). Another variant was reported to initiate from an upstream exon, herein named exon $1 \alpha$ (Fig. 5D), and contain also exon 2 (http://www.ensembl.org and http://blast.ncbi.nlm.nih.gov). This second variant composed of exon $1 \alpha$ and exon 2 was not detected in the tested cells (data not shown). Therefore, we focused 


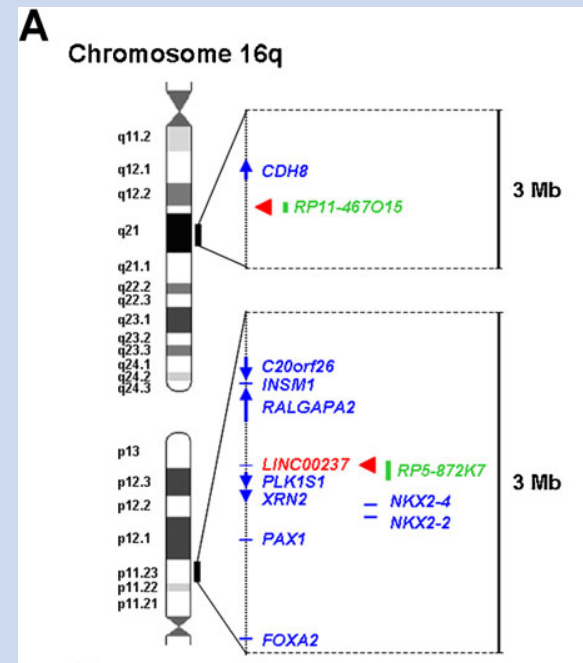

Chromosome 20p
B

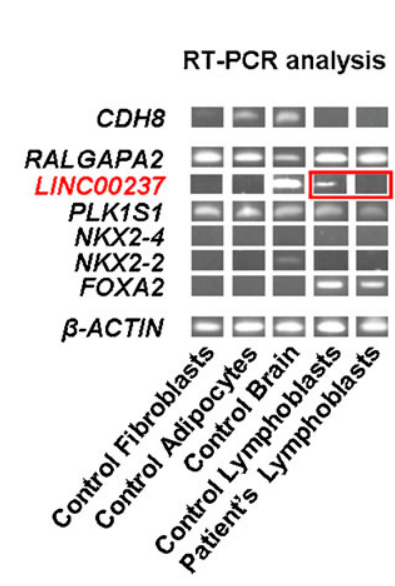

C

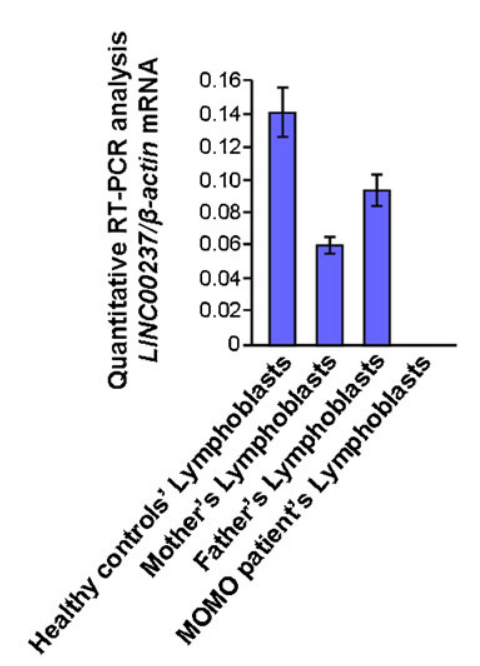

C

D LINC00237 gene

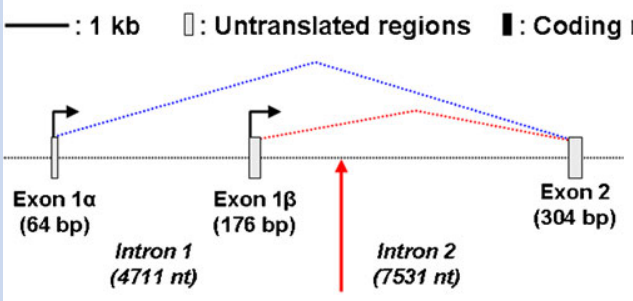

Chromosome 20p11.23 breakpoint

E

FIG. 5. Position, respective to breakpoints on chromosomes $16 q 21$ and 20p11.23 (A; from http://www.ncbi.nlm.nih.gov, http://www.ensembl.org, and $\mathrm{http} / / / \mathrm{www}$.genome.ucsc.edu/cgi-bin/hgGateway), and expression status [B-E] of candidate genes in normal cells and tissues and in MOMO patient B lymphoblasts. A: The region at breakpoint on chromosome 16 contains only CDH8 (Cadherin 8, type 2), located 601 kb upstream of the breakpoint. The region at breakpoint on chromosome 20 contains 10 genes and the breakpoint disrupts LINCO0237. B: Reverse transcription-polymerase chain reaction (RT-PCR) analysis of candidate genes, and (C) quantitative RT-PCR analysis of LINCO0237 in normal cells and tissues and in control and MOMO patient B lymphoblasts. In (B) and [C], LINC00237 was detected using primers within exon 2 [2-F and 2-R2, see Table]. D: Genomic organization of LINCO0237, alternative transcription initiation variants (arrows) and resulting splicing events (blue and red dotted lines), and position of the chromosome breakpoint. E: Complementary RT-PCR analysis of LINCO0237 transcripts in lymphoblasts from healthy individuals and from the MOMO patient and his parents, showing lack of transcripts joining exon $1 \beta$ and exon 2 and lack of transcripts containing exon 2 but not exon $1 \beta$ in MOMO patient cells, consistent with the position of the breakpoint (primers listed in Table).

our analyses on exon $1 \beta$-exon 2 transcripts. For both exon $1 \alpha$ - and exon $1 \beta$-initiated transcripts, only one potential 36 amino-acids open reading frame was detected in exon 2, but the candidate ATG initiating codon was not within a Kozak consensus sequence, suggesting that it was unlikely translated into a polypeptide and that LINC00237 was a npcRNA gene (Fig. 6) [Altschul et al., 1997, 2005]. Further RT-PCR analysis of LINC00237 transcripts confirmed lack of transcript amplification with primers located within exon 2 and also revealed the absence of transcripts joining exons $1 \beta$ and 2 in MOMO patient cells, and reduction of the latter in his parent's cells, consistent with the position of the translocation breakpoint (Fig. 5E). Transcripts containing exon $1 \beta$ but not exon 2 were equally amplified in lymphoblasts from healthy individuals and from the MOMO patient, indicating that disruption of LINC00237 upon chromosomal translocation does not alter transcription initiation but prevents synthesis of complete transcripts.

\section{Mutational Screening of LINCO0237}

Mutation screening of LINC00237 in our cohort of seven patients with MOMO-like syndrome revealed some polymorphisms. However, it did not reveal mutations even when searching for the nonsense, missense or splice-site types.

\section{DISCUSSION}

Homozygous balanced reciprocal translocations associated with a morbid phenotype are rare complications due to consanguinity, with only five publications describing the phenomenon to date [Leschot et al., 1986; Wilmot et al., 1990; Martinet et al., 2006; Baala et al., 2007; Zaki et al., 2007]. Chromosomal regions disrupted by these translocations can constitute a way to identify candidate genes for disorders. 
Potential 36 amino-acids ORF within exon 2:

aggctgctgATGctgaaggaaggagaaacgaggaggaagtgtccctgtggaca $\begin{array}{lllllllllllllll}M & I & K & E & G & E & T & R & R & K & C & P & C & G & 0\end{array}$

gtcatctcccttcatttaagccaggccagtagtccgggagacattctgaatgat

$\begin{array}{llllllllllllllllll}V & I & S & I & H & I & S & 0 & A & S & S & \text { P } & \text { G } & \text { D } & \text { I } & \text { I } & \text { N } & \text { D }\end{array}$

gcattatccTAG

A I $S$ *

FIG. 6. Potential open reading frame [ORF] within exon 2 of LINC00237. The absence of a Kozak consensus sequence, present on eukaryotic mRNA and playing a major role in the initiation of the translation process, around the putative ATG initiating codon suggests that this potential ORF is unlikely translated into a polypeptide and that LINC00237 is a non-coding RNA gene. As a reminder, the Kozak consensus sequence is [gcc] gccRccAUGG [ $R$ being a purine, adenine or guanine], upstream of the start codon (AUG), which is followed by another " $G$ ".

In our MOMO syndrome patient, the homozygous balanced reciprocal translocation $(16 ; 20)$ of bi-parental inheritance suggested, contrary to previous beliefs, an autosomal recessive mode of inheritance of this syndrome [Moretti-Ferreira et al., 1993; Zannolli et al., 2000].

A positional cloning strategy, combining fine FISH mapping with long range PCR analysis and Sanger sequencing, enabled us to precisely map the translocation breakpoints on both 16q21 and $20 \mathrm{p} 11.23$. On 16q21, there was only one possible candidate gene, CDH8 (cadherin 8, type 2), located $601 \mathrm{~kb}$ upstream from the breakpoint (Fig. 5A), but expression data and its very large distance from the breakpoint did not make it a likely candidate. On 20p11.23, the translocation disrupted of a novel npcRNA gene, herein named LINC00237. However, nine other genes were located within $1.5 \mathrm{Mb}$ of the breakpoint. As chromosomal breakpoints were in some cases reported to have an effect on the expression of genes located up to $1.3 \mathrm{Mb}$ away [Velagaleti et al., 2005], we investigated all 10 genes surrounding the breakpoint on chromosome 20 .

An expression study revealed that none of the expressed candidate genes, except LINC00237, showed significant variation between the lymphoblasts cells of our MOMO syndrome patient and controls. On the contrary, the mature transcripts of LINC00237 detected in normal lymphoblasts were totally absent in MOMO patient lymphoblasts, demonstrating that its disruption by the 20p11.23 breakpoint causes inactivation of this gene. Furthermore, LINC00237 was not ubiquitously expressed in control tissues (not expressed in adipose tissue), but it was notably highly expressed in the brain. Based on these findings, we hypothesize that LINC00237 could play a major role in the pathogenesis of MOMO syndrome. Notably, it was previously shown that npcRNA contribute to the regulation of gene expression in the nervous system [Iacoangeli et al., 2010]. In particular, we hypothesize that this non-protein-coding gene might be involved in hyperphagia and intellectual disability in MOMO syndrome. However, we cannot completely exclude the possibility that other LINC00237 transcripts, containing additional exons not identified in our RACE assays, might encode proteins whose loss-of-function could contribute to the pathogenesis of the MOMO syndrome.
It would have been very interesting to investigate the translocation $(16 ; 20)$ in other family members. To the best of our knowledge, his parents did not have other children, and there were no cousins or relatives with a MOMO syndrome phenotype.

Mutation screening of LINC00237 in patients with MOMO-like syndrome did not identify alterations. This might be explained by the fact that the patients studied did not present the entire clinical spectrum of MOMO syndrome. Moretti-Ferreira et al. [2011] recently screened for NSD1 mutations in 49 Brazilian patients with overgrowth syndromes, including three MOMO patients. No alterations of NSD1 were identified in the three MOMO patients [Moretti-Ferreira et al., 2011]. It might be of central interest to screen these patients for LINC00237 alterations.

Due to the difficulties performing functional studies in cultured cells, especially with respect to the cognitive and behavioral nature of some MOMO syndrome features, the complete demonstration of the nature of the gene(s) implicated and the comprehension of the pathogenic mechanisms will certainly require the generation of animal models. An interspecies comparison revealed an $87 \%$ similarity level between the mouse and the human sequences of LINC00237. This analysis also revealed a complete conservation on the mouse syntenic chromosomal regions of both $3 \mathrm{Mb}$ regions surrounding the translocation breakpoints on human 16q21 and 20p11.23 (http://www.ensembl.org). These sequence data indicate that it would be feasible, using LoxP site insertion by gene targeting and CRE-mediated recombination, to generate transgenic mouse models carrying translocations equivalent to the MOMO syndrome translocation [Smith et al., 1995; Van Deursen et al., 1995]. This type of model, as well as conventional knock-out mouse models, will allow to characterize LINC00237 physiological functions and to investigate its implication, as well as that of other weaker candidate genes surrounding the MOMO translocation breakpoints, in the pathogenesis of the MOMO syndrome.

In summary, this study is the first report identifying a candidate gene for MOMO syndrome. This novel gene, LINC00237, apparently generating a npcRNA, was highlighted after identification and molecular mapping of a homozygous balanced reciprocal translocation affecting 20p11.23. The translocation disrupted LINC00237, resulting in loss of production of complete transcripts. LINC00237 is therefore the best candidate gene so far for MOMO syndrome, at least for the patient investigated in our study. Further mutation screenings in MOMO patients and above-mentioned functional studies in transgenic mouse models are needed to characterize the function of this candidate gene and the consequences of haploinsufficiency.

\section{ACKNOWLEDGMENTS}

We wish to express our gratitude to the patient and his family for their cooperation and thank the technical staff of the CHU-Bordeaux for its help.

\section{REFERENCES}

Altschul SF, Madden TL, Schäffer AA, Zhang J, Zhang Z, Miller W, Lipman DJ. 1997. Gapped BLAST and PSI-BLAST: A new generation of protein database search programs. Nucleic Acids Res 25:3389-3402. 
Altschul SF, Wootton JC, Gertz EM, Agarwala R, Morgulis A, Schäffer AA, Yu YK. 2005. Protein database searches using compositionally adjusted substitution matrices. FEBS J 272:5101-5109.

Baala L, Briault S, Etchevers HC, Laumonnier F, Natiq A, Amiel J, Boddaert N, Picard C, Sbiti A, Asermouh A, Attié-Bitach T, Encha-Razavi F, Munnich A, Sefiani A, Lyonnet S. 2007. Homozygous silencing of T-box transcription factor EOMES leads to microcephaly with polymicrogyria and corpus callosum agenesis. Nat Genet 39:454-456.

Giunco CT, Moretti-Ferreira D, Silva AE, Rocha SS, Fett-Conte AC. 2008. MOMO syndrome associated with autism: A case report. Genet Mol Res 7:1223-1225.

Iacoangeli A, Bianchi R, Tiedge H. 2010. Regulatory RNAs in brain function and disorders. Brain Res 1338:36-47.

Leschot NJ, von den Velden J, Marinkovic-Ilsen A, Darling SM, Nijenhuis LE. 1986. Homozygosity for a $\mathrm{Y} / 22$ chromosome translocation: $t(\mathrm{Y} ; 22)$ (q12;p12/13). Clin Genet 29:251-257.

Martinet D, Vial Y, Thonney F, Beckmann JS, Meagher-Villemure K, Unger S. 2006. Fetus with two identical reciprocal translocations: Description of a rare complication of consanguinity. Am J Med Genet Part A 140A: 769-774.

Moretti-Ferreira D, Koiffmann CP, Listik M, Setian N, Wajntal A. 1993. Macrosomia, obesity, macrocephaly and ocular abnormalities (MOMO syndrome) in two unrelated patients: Delineation of a newly recognized overgrowth syndrome. Am J Med Genet 46:555-558.

Moretti-Ferreira D, Vieira GH, Domingues CEF, Lima RLLF. 2011. New mutations in Brazilian patients with overgrowth syndromes. Poster presentation at the 12th International Congress of Human Genetics, Montreal (Canada).

Smith AJ, De Sousa MA, Kwabi-Addo B, Heppell-Parton A, Impey H, Rabbitts P. 1995. A site-directed chromosomal translocation induced in embryonic stem cells by Cre-loxP recombination. Nat Genet 9: $376-385$.

Van Deursen J, Fornerod M, Van Rees B, Grosveld G. 1995. Cre-mediated site-specific translocation between nonhomologous mouse chromosomes. Proc Natl Acad Sci USA 92:7376-7380.

Velagaleti GV, Bien-Willner GA, Northup JK, Lockhart LH, Hawkins JC, Jalal SM, Withers M, Lupski JR, Stankiewicz P. 2005. Position effects due to chromosome breakpoints that map approximately $900 \mathrm{~Kb}$ upstream and approximately $1.3 \mathrm{Mb}$ downstream of SOX9 in two patients with campomelic dysplasia. Am J Hum Genet 76:652662.

Wallerstein R, Sugalski RD. 2010. A new case of MOMO syndrome. Clin Dysmorphol 19:1-4.

Wilmot PL, Shapiro LR, Casamassima AC. 1990. Disomic balanced reciprocal translocation. Clin Genet 38:126-127.

Zaki M, Shehab M, El-Aleem AA, Abdel-Salam G, Koeller HB, Ilkin Y, Ross ME, Dobyns WB, Gleeson JG. 2007. Identification of a novel recessive RELN mutation using a homozygous balanced reciprocal translocation. Am J Med Genet Part A 143A:939-944.

Zannolli R, Mostardini R, Hadjistilianou T, Rosi A, Berardi R, Morgese G. 2000. MOMO syndrome: A possible third case. Clin Dysmorphol 9: 281-284. 